\title{
Explorando el \\ hábitat sonoro y \\ sus efectos en la \\ infancia. El caso de \\ 'Violetta'
}

Exploring the sound habitat and its effects in childhood. The case of 'violetta'

\section{AMPARO PORTA}

Universitat Jaume I (Castelló, España) 


\section{Educación y Pedagogía}

Aceptado 18/02/2019

\section{Resumen}

Los últimos cincuenta años han supuesto un periodo de grandes cambios en la educación, en los que aparecen de manera destacada sus relaciones con la identidad y relaciones del niño con el entorno. Los medios audiovisuales están implicados en este cambio por su alto impacto en la infancia, por ello se hace necesario conocer las características de la música del cine y la tv para estudiar sus efectos y buscar alternativas educativas. Este artículo se centra en una pequeña parte del problema: el significado y sus relaciones con el hábitat sonoro. Por ello utiliza como metodología el análisis cuantitativo para estudiar las características de la banda sonora, el análisis musical para comprenderla y el análisis del discurso para acceder a su significado y posición social. Con todo ello se ha desarrollado un diseño de investigación que ha sido aplicado a un estudio de caso, la serie televisiva Violetta, como muestra de la música cotidiana preferida de una amplio sector de la población infantil. 


\begin{abstract}
The last fifty years have been a period of great change in education, appearing prominently relations with the child's identity and relationships with the environment.. The audiovisual media are involved in this change for its high impact on children, therefore it is necessary to know the characteristics of the music of film and tv to study its effects and seek alternative. This article focuses on a small part, meaning and its relations with the sound habitat. Therefore used as quantitative analysis method to study the characteristics of the soundtrack, musical analysis to understand and discourse analysis to access their meaning and status. With all this we have developed a research design that has been applied to a case study, Violetta TV series, as shown everyday favorite music from a large segment of the child population.
\end{abstract}

\title{
Keywords
}

\author{
Soundtrack · Quantitative analysis · Classification · Film and television \\ - Listening $\cdot$ Music $\cdot$ Music education
}

\section{Parte I}

Una de las formas más destacadas que tienen los niños de relacionarse con la música es a través de su inmersión cultural y, desde allí, sumergidos, observan y exploran los sonidos, canciones y géneros construyendo su hoja de ruta inicial para la comprensión del mundo sonoro. Todo ello se realiza con las formas de expresión que les proporciona su época y cultura en diálogo con el mundo y sus valores (Piaget, Inhelder, 1981; Vigotsky, 1995; Sloboda, 2005). De esta forma aprenden, interaccionando en un mundo en acción al que se incorporan cuando el tren ya está en marcha, sumergiéndose en su paisaje y construyendo sus señas de identidad en el viaje y sus estaciones. Las posiciones educativas que han acercado el niño a su entorno más próximo han sido los grandes motores de avance de la educación en los últimos cincuenta años, teniendo en el aprendizaje significativo una de las piedras de toque (Ausubel, Novak 
y Hanesian, 1976; Coll, 1988). Igualmente, desde corrientes postestructuralistas, Vigotsky (1995) establece la naturaleza mediadora de los signos como portadores de significado. Estos dos conceptos, signo y significado, unidos al sentido, es decir, a la presencia del sujeto en el discurso, son estudiados por la Semiótica (Ballón y Campodónico, 1990) constituyendo el foco de nuestro trabajo.

El entorno musical del niño actual no tiene precedentes en la Historia porque abarca, además del medio físico, el proporcionado por los Mass-Media, y ello obliga a una revisión educativa. El cine y la televisión forman parte de su vida cotidiana, constituyendo espacios con significado y sentido que se incorporan a su experiencia y conocimiento (Aguaded, 2004; Pintado, 2005; De Moragas, 1991). Y la música forma parte de ello (Delalande, Vidal y Reibel, 1995; Swanwick, 1991). Pero, además de todo ello, no podemos olvidar que el hábitat sonoro tiene carácter dinámico, por ello es importante estudiar sus repercusiones en la educación musical, porque afectan al conocimiento y comprensión de la música y su posición cultural en el mundo en el que viven. La exploración del entorno es la mejor forma de conocer las bases donde se instala la educación musical de nuestro tiempo, y también la mejor herramienta de que disponemos para investigar los contenidos musicales vivos del currículum porque tal como se pronuncia Tonucci: la escuela debe ser un reflejo de la vida (Tonucci, 1976). El entorno sonoro, social y cultural da lugar a las formas de expresión utilizadas por la comunidad de referencia, por ello se hace necesario considerar en educación sus múltiples espacios, dedicando atención a aquellos de máxima repercusión y refuerzo. La banda sonora del cine y la televisión forma parte del espacio vital y educativo del niño y contribuye al desarrollo del gusto, los valores y la identidad, requiriendo por ello de un acercamiento multimodal (Porta, 2014). Este trabajo forma parte de una investigación más amplia que tiene como finalidad conocer el hábitat sonoro y sus implicaciones en la educación y el currículum. Este artículo se centra en el caso de una serie televisiva de alto impacto en la infancia y preadolescencia: Violetta. Para conocerla hemos utilizado algunas formas de aproximación y desarrollado herramientas con los siguientes objetivos específicos Objetivo 1. Conocer la música que escuchan en la serie, Objetivo 2. Saber cómo es y dónde está situada y Objetivo 3. Conocer su sentido, dominios y tendencias. 


\section{La música en el contexto audiovisual}

Los niños ven y escuchan el mundo en pantallas mediante diferentes dispositivos y múltiples opciones (Giráldez, 2005). Entre todos ellos la televisión ocupa un lugar destacado durante varias horas cada día, tal como indican desde hace más de una década informes como CAC (2003) y Del Río, Álvarez y Del Río (2004). La banda sonora del cine y la televisión es música de la cotidianidad, transmitida de forma oral no escrita con difusión masiva a culturas heterogéneas (Porta, 2011a). Para su estudio se requiere de formas específicas de acercamiento porque la música habla desde su propio lenguaje adaptado al medio audiovisual (Porta, 2007). Sus implicaciones en educación son claras porque producen efectos en el pensamiento sonoro y en las características de la escucha (Schafer, 1977; Schaeffer, 1966; Sloboda, 2005). Desde la Psicología Cognitiva, especialmente en sus vertientes organicistas/estructuralistas, establecen un cambio de peso en las unidades de análisis para los desarrollos investigadores, proponiendo que sean molares, indescomponibles y vinculadas al significado (Pozo, 1989, ). La finalidad es evitar la atomización de estas unidades por su pérdida de significatividad. Pertenecen a ella la Escuela de la Gestalt (Perls, 1969), autores como Piaget (1981) y de forma destacada, Vigotsky, quien señala que toda función psicológica superior es inicialmente una función social (Vigotsky, 1981, ). Revisando los estudios internacionales sobre el tema, la música de la televisión ha sido estudiada por Beckers (1993), Bixler (2000) o Magdanz (2001). Y el programa Sesame Street, destaca el trabajo de Wolfe (2001) quien propone la observación, clasificación y descripción de los elementos musicales del programa como base para sus investigaciones en musicoterapia infantil.

\section{La importancia del entorno comunicativo y cultural}

Observado desde la comunicación, la sociedad proporciona al niño, mediante pantallas, fuentes de información y bases reguladoras, por ello autores como Buckingham (2002) consideran necesario buscar nuevas estrategias educativas para proteger los derechos de los niños como ciudadanos y consumidores. Y desde la Pedagogía Crítica, Giroux plantea la necesidad de actualizar la alfabetización para poder prosperar en el mundo moderno (Aronowitz y Giroux, 1991). Las corrientes multiculturalistas defienden igualmente 
al niño frente a aquellas consideraciones educativas planteadas en términos de adaptaciones a las necesidades del mercado (McLaren y Kincheloe, 2008).

Ya dentro del campo de la Psicología de la Música, Marshall, North, y Hargreaves (2005) proponen poner la música cotidiana en el centro de sus tareas considerando el contexto, la democratización de la música, y también la necesidad de revisión y evolución de los métodos de investigación para que estén al servicio de estas necesidades.

\section{La responsabilidad de la Educación Musical}

Finalmente, en educación musical, Hemsy de Gainza habla de la necesidad de deslizar la educación musical de las cuestiones técnico-didácticas a la comprensión de entorno (Hemsy de Gainza, 1997). Ya en España, Medrano y Aierbe (2008) y Navas, Iborra y Sampascual (2007) han estudiado las preferencias vinculadas a contextos y valores. Finalmente en educación musical, Porta (2001) Herrera, Cremades y Lorenzo (2010), Díaz e lbarretxe (2008) o Rusinek (2004) estudian sus contextos y significados. En cuanto a su presencia en el aula como instrumento educativo, disponemos de los trabajos de
Giráldez (2005) y monográficos en Comunicar 23 (2004) y Eufonía 12 (1998).

\section{Aproximación metodológica al estudio de las bandas sonoras infantiles}

Para estudiar el sentido y significado de la música de la televisión en los niños, utilizaremos como marco de referencia la Semiótica desde una mirada educativa, convirtiendo el campo, la televisión, en una serie de categorías. Seguimos a Umberto Eco quien nos orienta en el procedimiento: cotejar definiciones, establecer el campo semiótico en términos de vastedad y desorden para, finalmente, crear un modelo de investigación sometido a contradicción. De esta forma, dice, mantendremos la complejidad del campo proporcionándole estructura y convirtiéndolo en un sistema (Eco, 1978). Como marco específico hemos tomado el que propone Gómez-Ariza (2000) quien clasifica las unidades de representación y las variables responsables de la percepción y el recuerdo. Para comprender como se construye interiormente la música, nos apoyaremos en Sloboda (2005) y Vigotsky (2006). Finalmente, como metodología de análisis utilizaremos el análisis musical (Zamacois 1987), el sociológico (Kripen- 
dorff, 1990; Ibáñez, 1968) y el semiótico (Ballón y Campodónico, 1990; Talens, 1996) (Figuras 1 y 2 ).

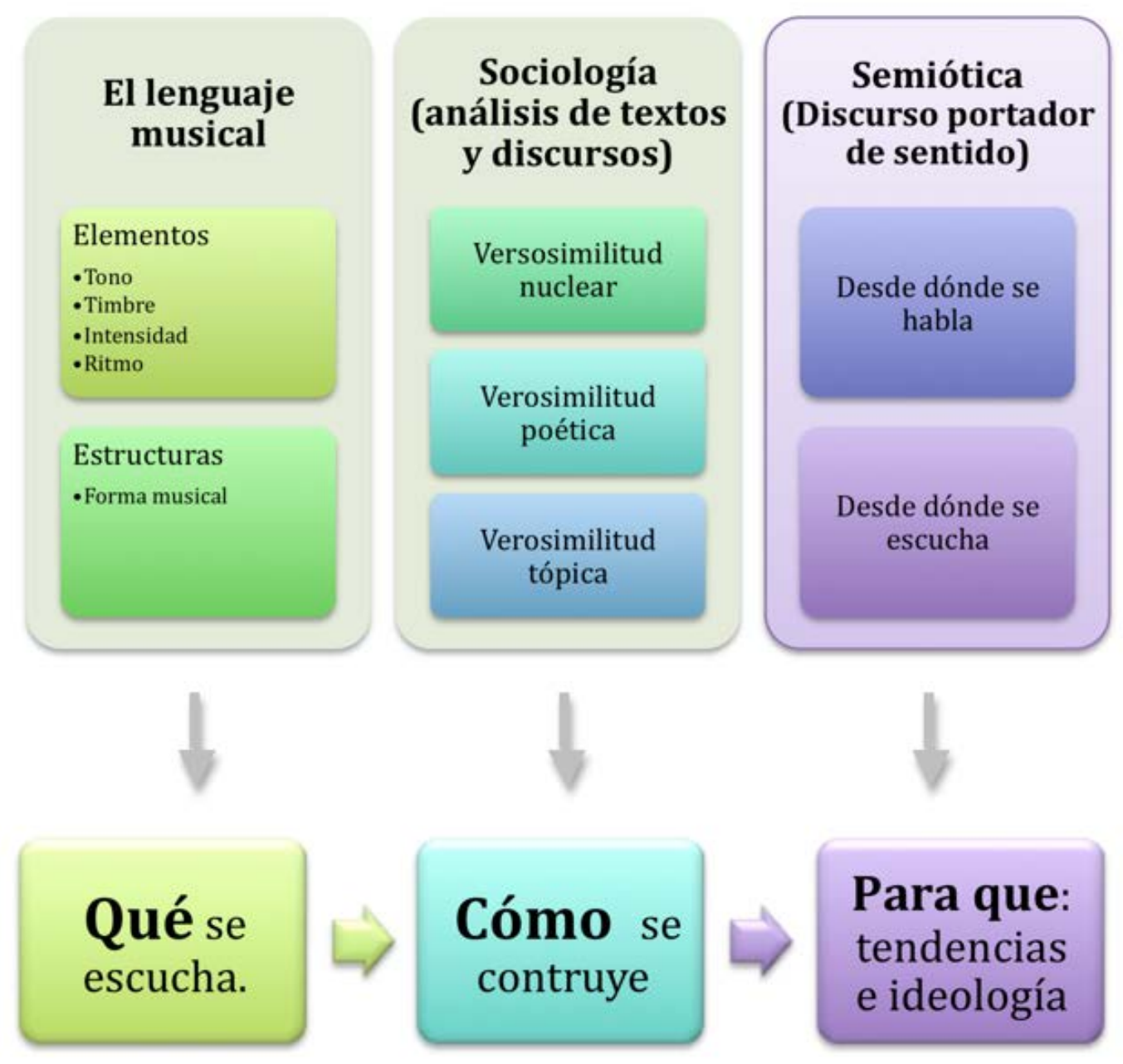

Figura 1.Qué, cómo y para qué la música cotidiana

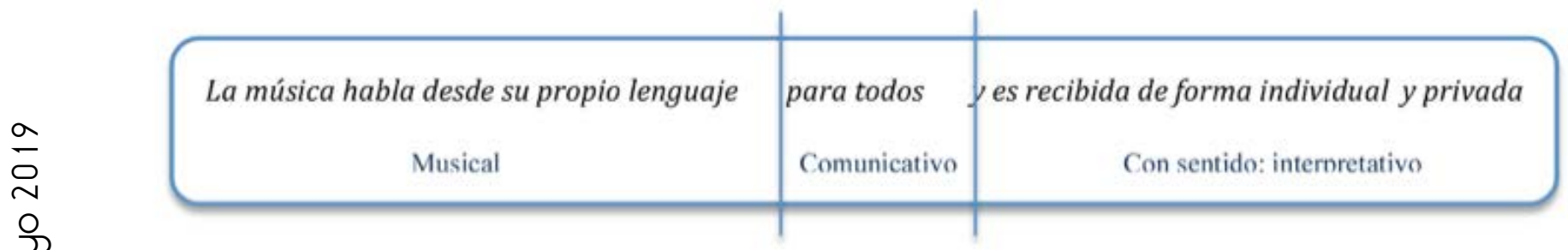

Figura 2. La música habla desde su propio lenguaje para todos y es recibida de forma individual y privada. 
La música habla desde su propio lenguaje. Por ello, utilizamos el análisis musical para desvelar los elementos del Lenguaje de la Música presentes en la TV, su estructura, usos estilísticos, formales y tímbricos (Zamacois, 1987).

Para todos. Mediante el análisis sociológico de textos y discursos accedemos a su función social, porque el mundo es sustituido por su discurso (Talens, 1996). Para su acercamiento Kripendorff (1990) propone tres grados de aproximación mediante niveles de verosimilitud. En nuestro caso, la verosimilitud nuclear muestra la parte más interior del discurso musical contestando a qué se escucha, la verosimilitud poética y lógica nos muestra la organización de la cadena comunicativa, respondiendo a dónde está, cómo es y se construye la música y, finalmente, la verosimilitud tópica da visibilidad a la tendencia comunicativa del discurso musical y su posición ideológica.

Es recibida de forma individual y privada. Finalmente llegamos a la escucha, elemento central de la música audiovisual, que se produce desde dos posiciones irreductibles: el lugar desde dónde habla y el lugar desde dónde se escucha (Porta, 2007). Acercándonos así al sentido, es de- cir, la posición del niño que escucha su serie favorita.

\section{Instrumentos de observación y análisis del discurso}

La elaboración de instrumentos para medir aspectos de la realidad musical y sus elementos ha sido una constante en nuestra Historia reciente, apareciendo Schaeffer como determinante en la década de los 60 y los 70, quien plantea el estudio fenomenológico de los modos de la percepción auditiva (Schaeffer, 1966). El segundo autor es Murray Schafer (1977) quien estudia la representación 'compositiva' del entorno sonoro y sus nuevas necesidades que, dice, formulan nuevas preguntas derivadas del cambio proponiendo que éste sea revolucionario. Ya en la primera década del siglo XXI Atienza da un paso adelante mostrando la necesidad de constituir la unidad elemental de un nuevo 'solfeo sonoro' que ha de tener como base una escala adecuada a las configuraciones de sus contextos (Atienza, 2004). La consideración de estos avances en unidades de análisis altamente sensibles al significado y su carácter molar nos han llevado a crear una encala de medida para estudiar el entorno sonoro cotidiano 
de los niños. En este artículo mostramos los resultados obtenidos en el estudio de la música de la serie Violetta, contestando a las siguientes preguntas de investigación: Qué música se escucha en la serie, cómo es, dónde está situada y cuáles son, sus dominios, tendencias y sentido. Para esta exploración se ha utilizado, el análisis de contenido a través de los niveles de verosimilitud, explicados anteriormente, y la plantilla 3.0.

La plantilla de la escucha fue creada 'Ad hoc' para esta investigación. Se desarrolló en el periodo comprendido entre 2007 y 2012. Para su elaboración se consideraron las características musicales más representativas susceptibles de medición. El instrumento utilizado ha sido la plantilla 3.0 y se ha realizado en 3 etapas: 1) Construcción de la plantilla piloto y validación mediante juicio de expertos (Nunes y Porta, 2008), 2) Segunda plantilla y validación interjueces (Porta y Ferrández, 2009) y 3) La plantilla 3.0 y su validación Porta, Morant y Ferrández, 2014) (Figura 3). Dicha plantilla se ha aplicado a diferentes productos audiovisuales y estudiado con el programa SPSS (Porta, 2014; Porta, Peñalver y Morant, 2013). Consta de 86 códigos distribuidos en 13 categorías: Sonido no musical y musical, Voz, Métrica y Rítmica, Tipo de Comienzo, Dinámica, Agógica, Género y Estilo, Organización Sonora, Cadencia, Modulación, Textura y Plano Sonoro (Porta, 2009; Porta, Morant y Ferrández, 2015). Estos indicadores se han mantenido desde los inicios del proyecto, y suponen en sí mismos un intento clasificador de la música del entorno, que consideramos valioso para el avance de la educación en los diferentes.

Nuestro interés se centra en el lado de la escucha, por ello, para contestar a nuestras preguntas hemos seleccionado el modelo, la metodología y situado sus elementos aplicando los niveles de verosimilitud del discurso. A través de ellos se han concretado en tres objetivos específicos que permitirán conocer mejor cuál es la presencia de la música en la serie en y la representación del mundo que ofrece. 


\title{
PARTE II.
}

\author{
El CAso de LA SERIE teleVisiva Violetta
}

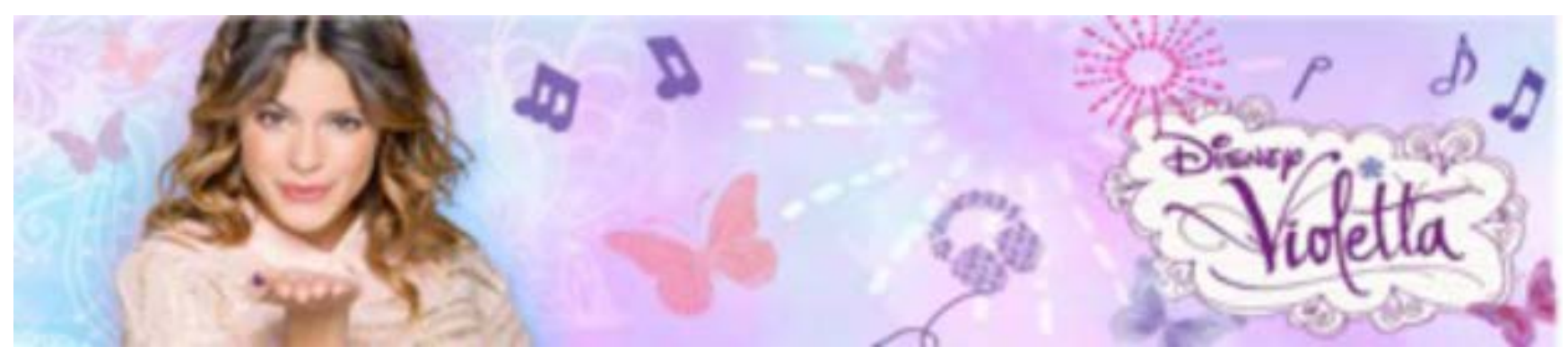

Figura 3. Imagen de la serie

\section{Objeto de estudio}

Durante su infancia el niño se ve inmerso en una cultura, nunca elegida, en la que construye su identidad utilizando modelos en el proceso, y los héroes y personajes de ficción juegan en todo ello un papel destacado. El objetivo de este estudio es conocer el discurso musical y su significación en la infancia de la serie televisiva Violetta (Figura 3). Para estudiarlo se creó el diseño de investigación, la elección de la muestra y la aplicación del cuestionario. Su finalidad fue conocer los gustos en materia audiovisual de 115 niños de 10 a 12 años, ordenando los resultados obtenidos con el programa SPSS en tres apartados. Apartado 1: Recoge los datos generales del niño o niña encuestado, edad, género, lugar de nacimiento y residencia, Apartado 2: Datos del encuestador sobre características del grupo, y Apartado 3: Recoge sus preferencias en cine, series, dibujos animados y reportajes, ocupando las diez primeras posiciones: Violetta (12,2\%), La que se avecina (10,4\%), Buena suerte Charlie (4,3\%), Código Lyoko (4,3\%), Austin y Alie (3,5\%), Big time rush (3,5\%), Carly (3,5\%), Jessie(3,5\%), Dragon Ball (2,6\%), Física y Química $(3,5 \%$, Los Simpson $(2,6 \%)$, y Shake it up $(2,6 \%)$. De las series, Violetta es la que quedó situada en primer lugar, se trata de una serie de televisión Argentina (2012) sobre una adolescente de clase acomodada que quiere ser cantante. La serie ha sobrepasado la expectativa de sus productores convirtiéndose en un verdadero fenómeno de masas emitido en varios países con productos, conciertos, CDs y firmas multitudinarias. En 
los episodios surge el amor, la amistad, la rivalidad, la moda, el espectáculo, la identidad y, de forma destacada como es habitual en estos productos audiovisuales, la intención implícita y explícita de que el espectador se identifique con sus personajes.

Historia. Esta adolescente, interpretada por Martina Stoessel, es huérfana de madre desde pequeña -de quien hereda sus condiciones para el canto- vive al principio de la serie con su padre en Madrid, entre adultos, regresando después a Buenos Aires donde recibe clases de piano en una escuela de música. Allí encuentra un entorno con sus mismas aficiones y se enamora de un joven en rivalidad con otro. En la segunda temporada aparecen y desaparecen personajes creando nuevas redes de conflictos y afinidades.

Descripción y audiencia. Violetta ha sido una telenovela infantil y juvenil de enorme éxito coproducida y difundida en Latinoamérica, Europa, Medio Oriente y África. Ha conseguido récords de audiencia tanto en Italia como en España, Israel y Francia destacando la franja de edad de 4 a 11 años. La música, es uno de sus factores de éxito, comercializada en tres $\mathrm{CDs}$, consiguió 4 discos de platino además de las versiones en Internet, libres y protegidas, así como visionados en youtube que alcanzan más de 50 millones en canciones como Esta soy yo. El rodaje fue realizado íntegramente en Buenos Aires y grabado en Alta Definición. Su presentación tuvo lugar en Disney Channel a finales de 2011 y unos días después en el programa Celebraton, donde la protagonista interpretó la canción Tu Resplandor por primera vez. A partir de entonces se sucedieron las promociones internacionales y visionados en youtube iniciados con la canción En mi mundo al que siguieron otros. Fue estrenada el 14 de mayo de 2012 en el canal Disney Channel y en España en el último trimestre de 2012, terminando la $2^{\text {a }}$ temporada en abril de 2014 e iniciada la tercera en verano de 2014.

El fenómeno. En la serie, la canción de apertura es En mi mundo traducida al italiano, francés, portugués, ruso, inglés, noruego, danés y sueco. Violetta dispone de su propia revista mensual con entrevistas, fotografías, juegos, pósters, álbumes, videojuegos y un gran catálogo para la venta de objetos de adorno y de vestir como mochilas, bisutería, objetos de papelería, perfumería y diferentes productos televisivos como resúmenes semanales de la serie y sus intérpretes adaptados a los 
países de emisión. La serie dio lugar a una película titulada Violetta en Concierto recogiendo muestras de la gira en Europa así como su cierre en Buenos Aires.

\section{Procedimiento}

Este estudio de caso ha tenido carácter exploratorio y ha sido desarrollado por expertos en dos fases con el siguiente procedimiento: búsqueda de los elementos sonoros y musicales, contestando así a la primera de nuestras preguntas ¿Qué música se escucha? $y$, en segundo lugar, estudiar su posición y sentido en la escena y la serie, contestando a Cómo es la música, dónde está situada, y sus dominios y tendencias, para acercarnos, finalmente, a sus posibles efectos. El estudio se realizó en el periodo comprendido entre febrero y abril de 2014 utilizando los episodios de Disney Channel emitidos en España, el DVD comercializado de Violetta en concierto, así como los datos descriptivos de la televisión argentina donde fue emitida inicialmente y de Youtube. Se escucharon diferentes episodios hasta seleccionar los utilizados en este trabajo, aplicándoles los instrumentos de medida mencionados. Igualmente se observaron sus productos asociados, la repercusión de la serie, su traducción y exportación a diferentes países con objeto de conocer su cobertura, realizando un seguimiento de algunos de sus conciertos en directo. En este trabajo hemos seleccionado dos canciones y dos ensayos, el estudio de audiencias de la serie y sus reproducciones en youtube. Las canciones y escenas elegidas han sido: 1 . En mi mundo, 2. Como quieres que te quiera (ensayo), 3. Yo soy así, 4. Yo soy así (ensayo). Se han utilizado como herramientas en las secuencias analizadas la plantilla 3.0 (Porta, 2009; Porta, Morant y Ferrández, 2015) y los niveles de verosimilitud, (Porta, 2007; Porta, 2014). Mostramos en este artículo los resultados obtenidos en el estudio de la banda sonora de algunas secuencias de la serie con objeto de conocer su discurso musical y significado.

\section{Metodología}

Actualmente no existe normativa que regule las características de las bandas sonoras que escuchan los niños. Así, pues, desde una mirada educativa, con objeto de conocer el discurso musical del cine y la tv infantil, en este estudio de caso hemos procedido a buscar sus elementos objetivos tomando como muestra cuatro secuencias de la serie. Para conocerla des- 
de su contexto narrativo desarrollamos un diseño ya utilizado en otras ocasiones, consistente en estudiar secuencias completas de los episodios elegidos, analizando su música. En relación a la elección del método y los instrumentos de recogida de datos en el sistema multimodal de la televisión, Ander-Egg (1987) y Olsson (2009) dicen que una vez detectado el problema y trazado el diseño que ha de seguir la investigación, hay que abordar los aspectos metodológicos, buscando aquellas soluciones que mejor se adapten a las necesidades. En nuestro caso utilizaremos el estudio de caso, el principal instrumento de recogida de datos será el vídeo así como los programas y productos colgados en youtube. Todo ello con intención de conocer los contenidos musicales de la serie, su audiencia y posibles efectos. Para ello hemos utilizado 10 horas de televisión y grabaciones comerciales asociadas, de las que ofrecemos en este artículo los resultados de una selección de 25 minutos como síntesis, un resumen del proceso, sus documentos más significativos y relaciones entre ellos. Para cubrir el objetivo específico 1 se aplicó el cuestionario de preferencias musicales, analizando y ordenando sus resultados con el programa SPSS (Porta 2015). De esta forma se eligió la serie Violetta, los capítulos y números musicales a estudiar, aplicando 27 veces la plantilla 3.0. Para cubrir el objetivo 2 se estudió la música en la serie, el capítulo así como la historia $y$, finalmente, el objetivo específico 3 se alcanzó interpretando música de la serie para los niños. Se han realizado cuatro análisis progresivos, el primero de carácter longitudinal, estudiando la serie en su conjunto, sus capítulos y las canciones hasta su elección final. El segundo y tercero estudian 13 características musicales utilizando las categorías de la plantilla 3.0 en las canciones, aplicando cortes en momentos significativos, y la forma musical. Finalmente, el cuarto análisis, de carácter interpretativo, ha permitido acceder al significado y sentido, estudiando el peso y lugar que ocupa la música en la serie para el niño-espectador. 


\section{Resultados}

\section{1. 'En mi mundo' 3'15”.}

Canción interpretada al aire libre, con escenografía y público

\section{Objetivo 1. Qué se escucha.}

Se aplicó 9 veces la plantilla 3.0 a la canción con los siguientes resultados: voz femenina con acompañamiento de teclado y percusión electrónicos, en el último tercio aparece una segunda voz grabada de la propia cantante. Acentuación binaria, estabilidad tonal, cadencias suspensivas y conclusivas alternadas, sin variaciones en la agógica ni la dinámica, música como figura y final conclusivo con voz solista.

Forma musical $A B C A B C B C$. Se trata de una canción estrófica en 4/4, tonalidad Fa $M$ con la tesitura del estribillo más aguda que la estrofa.

\section{Letra de la canción}

\section{Estrofa 1}

Ahora sabes que,

yo no entiendo lo que pasa

sin embargo se,

nunca hay tiempo para nada

pienso que no me doy cuenta

$y$ le doy mil y una vueltas

mis dudas me cansaron

ya no esperare

\section{Estribillo}

y vuelvo a despertar

en mi mundo

siendo lo que soy

y no voy a parar

ni un segundo

mi destino es hoy

\section{Objetivo 2. Como es y dónde está situada la música.}

Se trata de una actuación al aire libre con público que salta con los brazos en alto en un ambiente de fiesta con mucha luz, globos, focos encendidos en el escenario y coreografía. Comienza con la protagonista cantando mientras camina por un parque rodeada de gente joven. Al final de la primera estrofa la llevan al escenario donde comienza el estribillo con un grupo de rock con dos teclados, guitarra y coros de atrezzo, una mesa de mezclas, micrófonos y auriculares. La realización alterna las tomas al esce- 
nario, mostrando a músicos y bailarines, con las del publico. La relación entre música e imagen es sincrónica en la estrofa y no sincrónica en el estribillo. Se escucha completa terminando en cadencia conclusiva y aplausos.

El video tiene más de 40 millones de visualizaciones en youtube.

\section{Como quieres que te quiera (Ensayo)}

La escena consta de dos músicas que cubren aspectos diferenciados en la secuencia y la serie.

\section{Objetivo 1;Qué se escucha?}

Se aplicó 8 veces la plantilla 3.0 a las dos músicas de este número:

Música 1. Canción 'Como quieres que te quiera' 2'09' Canción estrófica. Música como figura, tímbrica: guitarra eléctrica, bajo, batería y voz femenina, acentuación binaria, monodía acompañada, estabilidad tonal en $\mathrm{Mi} \mathrm{M}$, comienzo tético, sin variación en la agógica ni la dinámica. Todos los motivos y partes analizadas terminan en IV grado excepto el cierre que termina con cadencia suspensiva en $\mathrm{V}$ grado.

\section{Letra de la canción}

Estofa 1.

Inicio $\mathrm{E}$, eh $\mathrm{O}, \mathrm{O}$

Dime lo que quieres

Y no me hagas llorar

No juegues conmigo

Me hagas a ilusionar

\section{Estribillo}

Como quieres que te quiera

Si te quiero y tu

No quieres que te quiera

Como yo quiero quererte

Música 2. Música como fondo en el diálogo de los personajes. Instrumental: piano y guitarra, acento ternario, mismo tempo que en la Parte I. Sin variaciones en la agógica, cambios dinámicos que siguen los diálogos, estabilidad tonal y la secuencia de grados: I, IV, I, IV, I. 


\section{Objetivo 2 Como es y dónde está situada la música}

Este ensayo aparece en el capítulo 39, temporada 2 y anticipa el lanzamiento de la canción como producto, que se produce en el capítulo siguiente, el 40.

Secuencia 1. Violetta aparece con traje de calle en el escenario hablando con el responsable de la producción y le solicita un ensayo para tomar contacto con el lugar, el responsable accede, prepara las luces y se retira. Los focos iluminan el escenario, se escuchan los pasos de la cantante caminando hacia el centro con su imagen a contraluz, queda sola y canta la canción con el acompañamiento instrumental pregrabado.

Música 1. Comienza con el sonido ambiente del escenario, los pasos y el clic del interruptor de los focos del escenario. Violetta canta la canción con sintetizador y batería repitiendo el estribillo con cierre suspensivo en el $\mathrm{V}$ grado.

Secuencia 2. Se acerca Diego que estaba escuchando entre bambalinas y comienza la música 2 como fondo mientras hablan.

Música 2. Comienza una melodía con piano acústico que pasa después a la guitarra mientras el piano acompaña, y termina con una larga resolución cadencial conclusiva durante el beso de los personajes. Esta parte de la escena utiliza música de fondo que se escucha con claridad durante el diálogo en un ambiente de intimidad y final conclusivo en una cadencia que se está esperando y presintiendo, como la trama, al final de la escena, que termina con un acorde arpegiado de guitarra.

En el capítulo siguiente, el número 40, tiene lugar la actuación que es el elemento central del capítulo que llega, finalmente, en el 36', desarrollándose en un escenario con público y dos chicas tocando guitarras con vestuario y maquillaje excesivo.

El vídeo tiene unos 52 millones de visitas en youtube en sus diferentes versiones. 


\section{3.a Yo soy así. (Ensayo)}

La escena consta de dos músicas que cubren dos aspectos de la historia:

\section{Objetivo 1 ¿Qué se escucha?}

Música 1. Estribillo (2 veces). Se ha aplicado la plantilla 4 veces en cada semifrase. Es música como figura, voz cantada por hombre y mujer de forma alternada por semifrases, monodía acompañada de sintetizador, acentuación binaria, comienzo tético, sin variación en la agógica ni la dinámica, estabilidad tonal, terminado en cadencia en todas las semifrases, siendo conclusiva únicamente en las estrofas que interpreta Violetta.

\section{Estribillo}

Es que yo soy así, mi vida es alocada Chica (4)

Siento que voy a mil, contigo todo cambia Chico (4)

Y es que yo soy así, con sólo una mirada Chica (4)

Vas a quedar de mí por siempre enamorada Chic

Música 2. Música instrumental como fondo. Se escuchan un pizzicato de violines, y contrabajos sintéticos, comienzo tético, acentuación binaria, sin variación en la agógica y cambios en la dinámica. Mantiene la tonalidad de Do $\mathrm{M}$ terminando todos los motivos en cadencia.

Objetivo 2. Cómo es y dónde está situada la música en la estructura narrativa.

La actuación pertenece a la temporada 2, capitulo 20, entre los minutos 5:04 a 7:21.

Escena. En un escenario de un plató de TV, la protagonista y un chico están ensayando la grabación de la canción con fondo instrumental grabado. Cuando nombran la palabra beso, comienza la música como fondo.

Música. Se trata de una secuencia armónica de 4 compases en 4/4 y tonalidad Do $M$ con sintetizador y apoyo de bajo electrónico. Aumenta y disminuye la intensidad a lo largo de la secuencia según la tensión dramática de la acción mientras los regidores 
hablan de la actuación. Comienza la música de nuevo cuando se van a dar un beso, en ese momento cambia, suena un breve diseño melódico suspensivo en los dos últimos compases se escucha un sólo con carillones que coincide con el beso de los protagonistas, y termina de forma súbita, con una cadencia suspensiva.

\section{3.b Yo soy así (Actuación) 3'37"}

\section{Estrofa 1}

Escucha y siente,

Sube el volumen vas a enloquecer,

Enloquecer enloquecer oh

Entiende y siente de corazones rotos

soy el rey, Yo soy el rey

soy el rey oh oh

\section{Estribillo}

Es que yo soy así, mi vida es alocada

Siento que voy a mil, contigo todo cambia

Y es que yo soy así, con sólo una mirada

Vas a quedar de mí por siempre enamorada

\section{Objetivo 1 ¿Qué se escucha?}

Se aplicó 14 veces la plantilla 3.0 con los siguientes resultados: música como figura interpretada alternándose hombre y mujer, monodía acompañada con sintetizadores que imitan guitarras eléctricas y percusión. Acentuación rítmica binaria, inicio tético, a veces a contratiempo sin variaciones en la agógica ni la dinámica, estabilidad tonal en Sib menor, terminando los semifrases con voz masculina en cadencia suspensiva, y conclusiva las de voz femenina.

Objetivo 2. Cómo es y dónde está situada la música.

Esta actuación tiene lugar en la temporada 2, capitulo 20, minuto 35:59 a 39: 26, al final del episodio. 
Escena. Es la grabación de la canción Yo soy así en un plató de televisión interpretada por Violetta y un chico, mientas Diego lo observa desde detrás de las cámaras y se alternan planos de personajes que ven la actuación desde casa.

Música: sintetizadores y batería electrónicos, voces dialogadas en el estribillo $y$ a dos voces por terceras en la estrofa. No hay instrumentos en la escena, aunque llevan micrófonos de rostro, pinganillos y se ven cámaras. Después de una parte hablada cantan de nuevo $y$, finalmente, se dan un beso cambiando inmediatamente el plano a los técnicos de detrás del escenario y a los personajes que ven la escena en la televisión, desde sus casa.

Tiene mas de 50 millones de visitas en youtube.

\section{Conclusiones}

Este artículo ha tenido como objetivo conocer la música que escuchan los niños en entornos sonoros mediáticos con tres objetivos específicos: 1) Conocer la música que escuchan, 2) Estudiar como es y dónde está situada y 3) Interpretar su sentido, dominios y tendencias. Para ello se estudió la música en el contexto audiovisual, revisaron las investigaciones recientes en el campo y sus conexiones con otros estudios educativos y culturales, realizando con todo ello su justificación y aproximación metodológica. Para responder al objetivo general de la investigación se han aplicando los niveles de verosimilitud al discurso musical, descriptivo, comunicativo y de sentido. Estos principios y metodología se han aplicado a la serie Violetta. Con la verosimilitud nuclear hemos conocido las características de su banda sonora, la verosimilitud poética y lógica nos ha mostrado como está construido el discurso musical, y través de todo ello hemos accedido a la verosimilitud tópica, es decir, sus tendencias discursivas e ideológicas desde lo sonoro (Porta, 2007).

Como respuesta al objetivo específico 1. Conocer los elementos musicales. Podemos decir que la serie utiliza voces solistas, instrumentos del pop/rock y orquesta sintética, destacando en esta última la cuerda y la percusión. Predomina la acentuación binaria y los cambios de intensidad por edición, se utilizan distintas tonalidades, modos mayores y menores, canciones y estribillos completos así como motivos descriptivos con sonidos 
electrónicos y acústicos, cambios bruscos y silencios súbitos.

Respondiendo al objetivo específico 2. Cómo es y dónde esta situada la música. Hemos revisado la serie, que podríamos resumir como musical, y sus capítulos, todos ellos con interpretaciones musicales. Las canciones se escuchan enteras al menos una vez, con versiones más breves que aparecen como ensayos incorporados en la trama. La música se escucha en los dos planos sonoros, como figura, en el caso de las canciones, y como fondo, en los diálogos entre personajes. Las canciones siguen la forma estrófica habitual de la música pop actual, $A B$ con una pequeña introducción, posición de figura, intensidad fuerte e instrumentos en escena que no siempre responden a lo escuchado. Cuando actúa como fondo es instrumental y suena como acústica, se escuchan guitarras, familia del violín y carillones, tempos más pausados y motivos melódicos con acentuación ternaria y binaria, silencios súbitos y secuencias descriptivas en claro contraste con las canciones. La música es diegética, interpretada por los propios personajes, en el caso de las actuaciones, y no diegética cuando aparece como fondo, creando el clima emocional y afectivo de la escena. En todos los ca- sos son músicas originales creadas para la serie con una buena sincronía con la imagen más cuidada en los estribillos que en las estrofas. Finalmente, respondiendo al objetivo específico 3. Valoración de la banda sonora, estudio de tendencias y dominios culturales. La serie tiene una audiencia destacada en el tramo de edades de 4 a 11 años, ocupando la música una parte importante del eje argumental, situado en el centro de motivación de la protagonista. Las canciones se preparan en capítulos anteriores creando la expectativa de la actuación. Existen dos clases de músicas en la serie: actuaciones y fondo en diálogos de personajes. Las primeras muestran las canciones como producto acabado, las segundas representan la voz del narrador, el que más sabe de la historia, y también del espectador, proporcionándole desde la proximidad, elementos emocionales y conmovedores de identificación, subrayando así el objeto de deseo. Las canciones forman parte de la narrativa de la serie de forma explícita mediante ensayos, y también con segundas músicas incorporadas en los diálogos en momento álgidos de la trama, en las que van a hurtadillas, mostrando su gran cualidad oculta en palabras de Cóppola (1997), que su presencia pase inadvertida al espectador. Así, actuando desde el fon- 
do, este backstage musical contribuye al éxito de la serie que tiene reproducciones miIlonarias en Internet con máximos en canciones como Yo soy así (50 millones) y Como quieres que te quiera (32 millones), letras que hablan de mundos ideales y amor, y venta de productos asociados. Igualmente se observa como tendencia en las canciones, frases y motivos, cierres conclusivos asociados al personaje principal, proporcionando estabilidad, refuerzo e identificación. $Y$ dualidades con asociaciones musicales: realidad-ficción, proximidad-espectáculo, fondo-figura, ensayo-actuación, acústico-electrónico, correspondiendo el primer elemento de cada uno de estos binomios a la música como fondo y el segundo a la música como figura.

El significado y sentido de la música que ven y escuchan los niños en los medios masivos de comunicación se produce en el espacio de la escucha, por ello tiene que ser estudiado desde la proximidad. Para conocer este territorio sonoro se requiere de la suma de estudios de caso, donde también se encuentran sus límites, por ello esperamos ampliar este mapa con estudios sucesivos. De momento hemos utilizado unidades molares de análisis para la búsqueda de significado, poniéndonos en el caso del niño o la niña que ve y escucha su serie favorita, y desde este ángulo hemos contestando nuestras preguntas. Esta serie forma parte de la experiencia vital y representación del mundo de los niños que la siguen. Y la música, en este espacio de expectativa, identificación y objeto de deseo, dice cosas que la palabra y la imagen, no tienen tiempo, no quieren o no pueden decir. Estudiar los efectos que la música audiovisual produce en la infancia desde una mirada educativa es un reto que sólo es posible abordar contemplando los dos espacios en los que se produce, el lugar desde el que habla -las pantallas y sus múltiples dispositivos- y el lugar desde donde se escucha -el del niño que ve en su casa, en este caso, su serie favorita.

\section{Agradecimientos}

Este trabajo ha sido posible gracias a la ayuda proporcionada por los proyectos:1) I+D (2007/ 2010) (P1 1A2007-17); 2) Cooperación Interuniversitaria e Investigación Científica entre España e Iberoamérica (A/018075/08), 3) I+D (2010/ 2012) (P11B2010- 
37) y 4) 'La televisión como hábitat sonoro. Estudio de los efectos de la banda sonora y sus narrativas audiovisuales en la infancia' (Edu2012-36404) IP: Amparo Porta I+D Nacional 2013 a 2015. Proyectos de Investigación Fundamental no Orientada.

\section{Bibiliografía}

Aguaded, J. (2004). Música y Comunicación. Comunicar, 23: 9-22.

Aronowitz, S. y Giroux, H. (1991). Postmodern education: Politics, culture, y social criticism. University of Minnesota Press.

Atienza, R. (2004). L'identité sonore: une variable essentielle dans la configuration urbaine. Grenoble, Cresson.

Ausubel, D. Novak, J y hanesian, H. (1976). Psicología educativa: Un punto de vista cognoscitivo. México, Trillas.

Ballón, E. y Campodónico, H. (Trad. Greimas y Courtés) (1990). Semiótica: Diccionario razonado de la teoría del lenguaje. Madrid, Gredos.

Beckers, R. Walkman, Fernsehen, Lieblingsmusik. (1993). Merkmale musikalischer Frühsozialisation. Musikpädagogische Forschung, 14: 11.

Buckingham, D. (2002). Crecer en la era de los medios electrónicos, Morata.

Bixler, B. (2000. Let's make music. School Library Journal, 46 :11-72.

CAC. (2003). Libro Blanco: La educación en el entorno audiovisual. Consejo audiovisual de Cataluña. 
Coll, C. (1988). Significado y sentido en el aprendizaje escolar: Reflexiones en torno al concepto de aprendizaje significativo. Infancia y Aprendizaje. 41:131-142. http:// dx.doi.org/10.1080/02103702.1988.10822196

Delalande, F., Vidal, J. y Reibel, G. (1995). La música es un juego de niños. Buenos Aires: Ricordi.

Del Río, P. y Alvarez, A. y otros. (2004). Pigmalión. Informe sobre el impacto de la televisión en la infancia. Madrid, Fundación Infancia Aprendizaje.

De Moragas, M. (1991).Teorías de la comunicación. Barcelona: Gustavo Gilli.

Díaz, M. e lbarretxe, G. (2008). Aprendizaje musical en sistemas educativos diversificados. Revista de Psicodidáctica, 1: 97-110.

Eco, U. (Trad. Cantarell. (1978). La estructura ausente: Introducción a la semiótica. Madrid, Lumen.

Gómez-Ariza, C., Bajo, T. y others, (2000). Cognición musical: relaciones entre música y lenguaje Musical. Cognitiva, 12. FIA: 63-87.

Hemsy De Gainza, V. (1997). La transformación de la educación musical a las puertas del siglo XX1. Editorial Guadalupe.

Herrera, L., Cremades, R. y Lorenzo, O. (2010). Preferencias musicales de los estudiantes de educación secundaria obligatoria. Cultura y Educación 243; n, 22(1) :37-51. http://dx.doi.org/10.1174/113564010790935222

Ibáñez, J. (1979). Interpretación y análisis. Más allá de la sociología. El grupo de discusión, técnica y crítica. (pp. 333-351). Madrid. Siglo XXI. 
Kincheloe, J. L., McLaren, P. y Steinberg, S. R. (2011). Critical pedagogy y qualitative research. Denzin, N., y Lincoln, Y (4 th Ed.) The SAGE hybook of qualitative methods in health research: 163-178.

Kripedorff, K. (1990). Metodología de análisis de contenido. Teoría y práctica. Barcelona, Paidos.

Magdanz, T. (2001). Classical music: Is anyone listening? A listener-based approach to the soundtrack of Bertry Blier's Too beautiful for you. Discourses in music, $3: 1$.

Marshall, N., North, A. y Hargreaves, D. (2005). Educación musical en el siglo XXI: Una perspectiva psicológica. Eufonía: Didáctica de la Música, 34 :8-32.

Medrano, C. y Aierbe, A. (2008). La dieta televisiva y los valores: un estudio realizado con adolescentes en el País Vasco. Revista Española de Pedagogía, 239 : 65-84.

Navas, L., Iborra, G. y Sampascual, G. (2007). Las metas académicas de los estudiantes de ESO en la clase de música. Revista de Psicodidáctica, 12 (1) : 131-142.

Nunes, J. y Porta, A. (2008). La bya sonora de la televisión infantil entre la globalización y la diversidad cultural. Río de Janeiro: UNIRIO.

Perls, F. (1969). Ego, hunger y aggression: The beginning of gestalt therapy. New York, Vintage.

Piaget, J. y Inhelder, B. (1981). Psicología del ni-o. Madrid, Morata.

Pintado, J. (2005). Lo ideal y lo real en TV: calidad, formatos y representación. Comunicar, 25: 101-108. 
Porta, A. (2014a). Explorando los efectos de la música del cine en la infancia. Arte, Individuo y Sociedad, 26 (1): 82-98. http://dx.doi.org/10.5209/rev_aris.2014.v26. $\mathrm{n} 1.40384$

Porta, A. (2014b). Los modos de escucha televisiva. Música y audición en los géneros audiovisuales. Public Universitat de Barcelona. J. Gustems (Coord) 13:53 -67.

Porta, A. (2011a). La oferta musical de la programación infantil de «TVE» como universo audible The Musical Offers of Children's Programming on «Televisión Española» as its Hearing Universe. Comunicar, 19(37), 177-185.

Porta, A. (2007). Músicas públicas, escuchas privadas. Hacia una lectura de la música popular contemporánea. Aldea Global. Barcelona, UAB, UV, UJl.

Porta, A., Peñalver Vilar, J. M. y Navasquillo, R. M. (2013). Music of the Inaugural Ceremony of London 2012: A Performance among Bells. International Review OfThe Aesthetics y Sociology Of Music, 44(2) : 253-276.

Pozo, J. (1989). Teorías cognitivas del aprendizaje. Madrid, Morata.

Rubio, M., Coppola, F. y Saada, N. (1997). El cine americano actual: Conversaciones con Francis Ford Coppola, Brian DePalma, Martin Scorsese, Clint Eastwood, Michael Cimino, John Carpenter, Joe Dante, Joel y Ethan Coen, Tim Burton. Madrid: J.C.

Rusinek, G. (2004). Aprendizaje musical significativo. Revista Electrónica Complutense de Investigación en Educación Musical, (1), 5.

Swanwick, K. (1991). Música, pensamiento y educación (Vol. 24). Ediciones Morata.

Schaeffer, P. (1996). Traité des Objets Musicaux. Paris. Seuil.

Schafer, M. (1997). The tuning of the world, p.205. Toronto: McClell y Steward. 
Sloboda, J. (2005). Exploring the musical mind: Cognition, emotion, ability, function. Oxford University Press.

Talens, J. (1996). Escritura contra simulacro: el lugar de la literatura en la era electrónica. Casa de las Américas.

Tonucci, F. (1976). La escuela como investigación, Barcelona: Avance.

Vigotsky, L. (1981). The instrumental method in psychology. J. Wertsch: The Concept of Activity in Soviet Psychology, pp. 134-143. New York, Sharpe.

Vigotsky, L. (2006). La imaginación y el arte en la infancia/The imagination y the art in childhood. Madrid: Akal.

Vigotsky, L. Kozulin, A. y Abadía, J.P. (1995). Pensamiento y lenguaje. Barcelona: Paidós.

VVAA, (1988). Monográfico Música moderna Eufonía,12. Barcelona: Graó.

Zamacois, J. (1987). Teoría de la música, vol. 1 y 2. Barcelona: Labor.

Wolfe, D. y Stambaugh, S. (1993). Musical analysis of sesame street: Implications for music therapy practice y research. Journal of Music Therapy. http://dx.doi.org/10.1093/ jmt/30.4.224 